\title{
Comparative study of reactive power control methods for photovoltaic inverters in low- voltage grids
}

ISSN 1752-1416

Received on 21st November 2014 Revised on 2nd August 2015 Accepted on 14th September 2015 doi: 10.1049/iet-rpg.2014.0402 www.ietdl.org

\author{
Arash Momeneh ${ }^{1}$, Miguel Castilla ${ }^{1}$, Jaume Miret ${ }^{1}$, Pau Martí ${ }^{2}$, Manel Velasco ${ }^{2}$ \\ ${ }^{1}$ Department of Electronic Engineering, Technical University of Catalonia, Avda. Víctor Balaguer s/n, 08800 Vilanova i la Geltrú, Spain \\ ${ }^{2}$ Automatic Control Department, Technical University of Catalonia, Pau Gargallo 5, 08028 Barcelona, Spain \\ E-mail: arash.momeneh@upc.edu
}

\begin{abstract}
The increasing installation of photovoltaic panels in low-voltage grids causes an over voltage problem, especially during high production and low consumption periods. Generally the over voltage problem is overcome by implementing reactive power control methods. The advances in networked control systems theory and practice create new scenarios where reactive power control methods can offer additional features and benefits. To explore these new capabilities, this study presents two new reactive power control methods that exploit the networked approach. These two methods are evaluated in a comparative reference framework that also includes the base-line case where no reactive control method is applied, the conventional droop method approach, and a solution based on a near-optimal location of a high power STATCOM derived from one of the new proposed networked methods. The main merit factors used to compare the control methods are the maximum voltage across the distribution grid, the power factor in the point of common coupling, and the total power losses and economic cost of the installation. With these merit factors, the advantages and limitations of the new and existing control methods are revealed and discussed. A useful discussion for selecting the best control solution is also reported.
\end{abstract}

\section{Introduction}

Solar photovoltaic (PV) power is a commercially available and reliable technology with a significant potential for long-term growth [1-13]. A possible location for PV panels is in residential areas where they form a low-voltage (LV) distribution grid. The increasing amount of PV facilities may cause an over voltage problem in this power grid scenario, especially for high production and low consumption situations [14-18]. This problem is even magnified where power lines with high $\mathrm{R} / \mathrm{X}$ ratios are used [18].

Traditionally, the over voltage problem has been solved by reactive power compensation methods [19-26]. The conventional technique is based on a droop function $[19,20]$. Using this technique, reactive power is supplied according to the local measured voltage and without any communication network. The advances in networked control systems, where low bandwidth communication infrastructure links cooperating entities, offer new scenarios to possibly improve the performance of conventional techniques and/or to achieve complementary operating features. For example, in [21-23], the local data is sent to all the PV units with the aim of equalising the reactive power injection. In addition, non-linear control techniques have been used to optimise the operation of these systems, such as fuzzy logic in [24], neural network in [25], swarm optimisation in [26], and genetic and evolutionary algorithms in [27-29]. Control algorithms with better performance are expected using these techniques as discussed in [29]. Given that the control is normally distributed among the PV units, the non-linear techniques also require using the low-bandwidth communication infrastructure. Other advanced control techniques requiring fast communication channels, such as the solutions based on multi-agent intelligent systems were presented in $[30,31]$. However, these techniques are not considered in this study due to the implementation complexity and the extra economical cost. As an alternative to previous solutions, distributed STATCOMs have been used to reduce the voltage profile of a LV grid $[32,33]$. The location of the

STATCOMs is analysed and discussed in detail in [33], although it is really an open topic that requires further examination. Finally, even noting that there is a great variety of existing solutions, few comparative studies are available in the literature. In particular, probabilistic based studies compared compensation techniques for PV installations in [34] and wind generators in [35].

The previous discussion indicates that (i) a great research effort has been conducted over the past decade to the development and improvement of techniques for reactive power compensation in LV distribution grids, (ii) the benefits of taking advantage of a communication infrastructure have not been fully explored, (iii) few studies have focused on constructing a thorough and useful comparison reference framework for future LV grid design. The contribution of this paper is twofold. First, it proposes two new reactive power control methods that permit further investigation of the benefits that a communication infrastructure can bring to LV grid operation with voltage regulation. Both have comparable communication requirements although one is based on a multi-master paradigm while the other one follows a master-slave configuration. In addition, one is based on a linear control scheme while the other one is based on non-linear control approach. Second, the paper presents a comparative study of new and existing reactive power compensation techniques in LV grids from the viewpoint of technical performance and cost. Five scenarios are considered. The first one is only used for base-line comparative purposes and is the case where no reactive power injection applies. The second one is the conventional droop compensation strategy. The third and fourth scenarios correspond to the new strategies presented in this paper. The fifth scenario is a single STATCOM solution with no communication, with a simple linear control scheme, but with an optimal-inspired location within the grid.

The comparison is carried out with a simulation model, developed in MATLAB ${ }^{\mathcal{O}}$ using the SymPowerSystems toolbox, and valid for the five considered scenarios. The power system is based on real data from a residential area located in Brædstrup, a village in the region of Østjylland, Denmark [36]. The main merit factors used to compare the control techniques are the maximum voltage across the distribution grid, the power factor in the point of common 


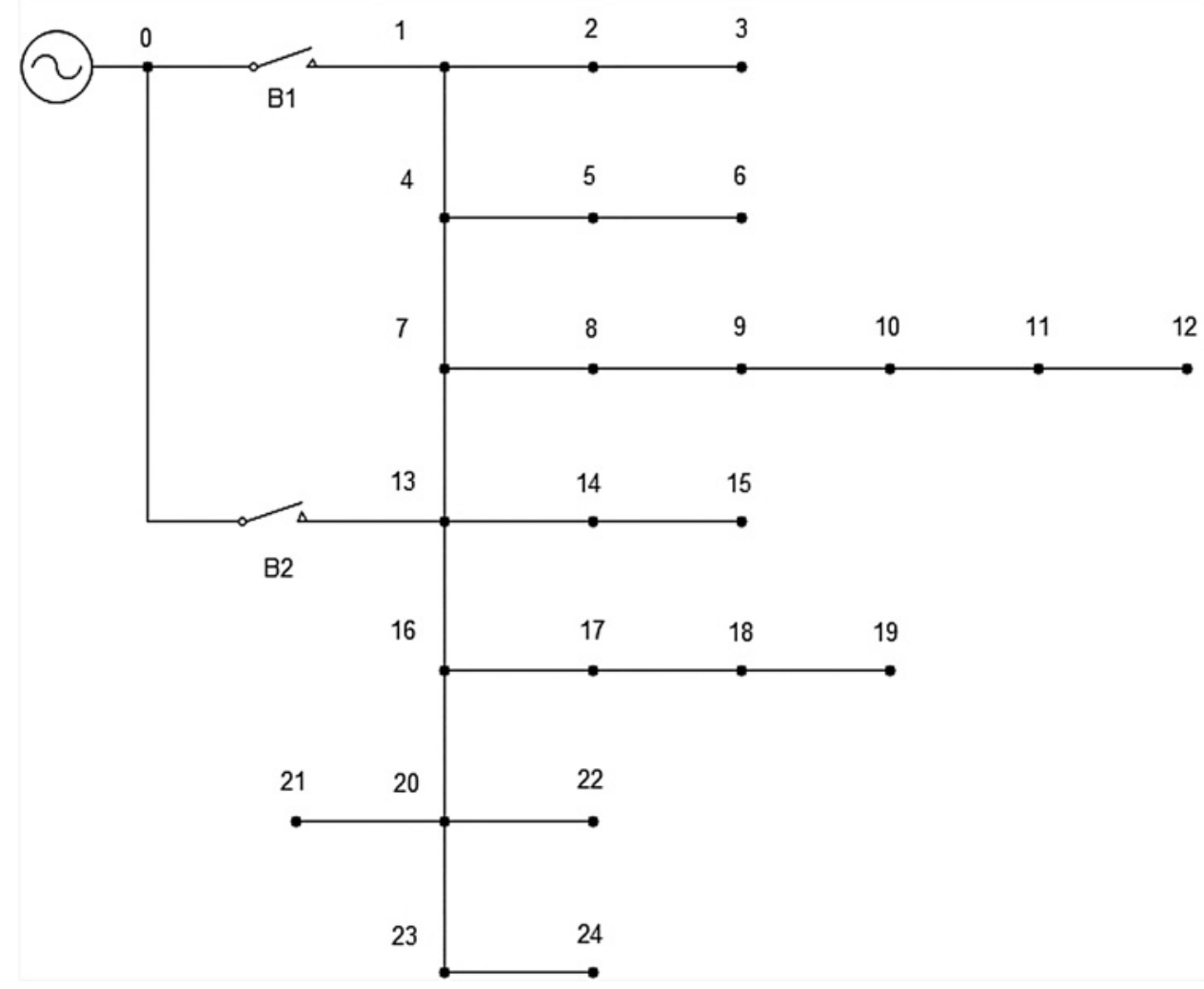

Fig. 1 Single-line diagram of the LV grid

coupling, and the total power losses of the installation. In addition, economical cost is also included. Useful discussion for selecting the best control solution for the considered practical scenario is also reported.

The rest of the paper is organised as follow. In Section 2, the configuration of the LV grid is described. Section 3 presents the two new control strategies for reactive power compensation while describing the other scenarios considered in the performance analysis. In Section 4, the advantages and limitations of the evaluated control techniques are revealed through the analysis of the measured merit factors. Finally, the paper is concluded in Section 5 with remarks regarding the results.

\section{LV grid configuration}

The power system considered in this paper is explained next. Fig. 1 shows the configuration of the LV grid under study. The medium voltage (MV) grid (including the MV to LV transformer) is modelled as an ideal voltage source which is connected to the node 0 of the installation. Downstream of this source, a meshed topology with 24 nodes is built. Two breakers, B1 and B2, are normally closed to increase the power transfer capacity of this system. Underground cables are used in the installation to interconnect the source, breakers, and nodes. The impedance values of these cables are listed in Table 1.

Fig. 2 shows the PV generators and the local loads included in the node $j$ of the LV grid (for $j=1$ to 24). The figure also draws the line impedances between the nodes $i-j$ and $j-k$. For simplicity, this study considers that all the PV generators have the same power production $\left(P_{i}=10 \mathrm{~kW}\right)$, although in the practical installation the solar modules have different sizes.

In the presented LV grid, the over voltage problem is caused by the power production of the PV generators. The impedance of the interconnecting lines is mainly resistive (see Table 1) and thus the injection of active power to the grid notably increases the local voltage at each node. The worst case scenario corresponds to a situation characterised by the maximum power production and minimum power consumption. This is, in fact, a realistic situation which is experienced during the daily hours with peak solar irradiation and a very low consumption in residential areas (typically between 12 to $13 \mathrm{~h}$ in weekdays). This problem is typically overcome thanks to the capacity of the PV inverters to absorb reactive power. Different compensation techniques will be presented in the next section.

\section{Reactive power compensation techniques}

This section presents two new reactive power control methods developed on the basis that a communication infrastructure can be used to exchange information among the PV inverters. In addition, the other three scenarios considered in the performance analysis are also described. From a constructive point of view, the five scenarios are ordered as follows: (i) base-line case where no reactive power control method is applied, (ii) conventional droop method, (iii) and (iv) correspond to the new networked control methods, and (v) solution based on a near-optimal location of a

Table 1 Single-line impedance values of the underground cables

\begin{tabular}{lccccc}
\hline Lines & Nodes & Impedance, $\mathrm{m} \Omega$ & Line & Node & Impedance, $\mathrm{m} \Omega$ \\
\hline 1 & $0-1$ & $22.4+j 5.7$ & 14 & $11-12$ & $11.2+j 2.9$ \\
2 & $0-13$ & $67.2+j 17.2$ & 15 & $13-14$ & $22.4+j 5.7$ \\
3 & $1-2$ & $11.2+j 2.9$ & 16 & $13-16$ & $22.4+j 5.7$ \\
4 & $1-4$ & $22.4+j 5.7$ & 17 & $14-15$ & $11.2+j 2.9$ \\
5 & $2-3$ & $11.2+j 2.9$ & 18 & $16-17$ & $22.4+j 5.7$ \\
6 & $4-5$ & $11.2+j 2.9$ & 19 & $16-20$ & $22.4+j 5.7$ \\
7 & $4-7$ & $22.4+j 5.7$ & 20 & $17-18$ & $11.2+j 2.9$ \\
8 & $5-6$ & $11.2+j 2.9$ & 21 & $18-19$ & $11.2+j 2.9$ \\
9 & $7-8$ & $11.2+j 2.9$ & 22 & $20-21$ & $11.2+j 2.9$ \\
10 & $7-13$ & $33.6+j 8.6$ & 23 & $20-22$ & $11.2+j 2.9$ \\
11 & $8-9$ & $11.2+j 2.9$ & 23 & $20-23$ & $22.4+j 5.7$ \\
12 & $9-10$ & $11.2+j 2.9$ & 25 & $23-24$ & $11.2+j 2.9$ \\
13 & $10-11$ & $11.2+j 2.9$ & & & \\
\hline
\end{tabular}




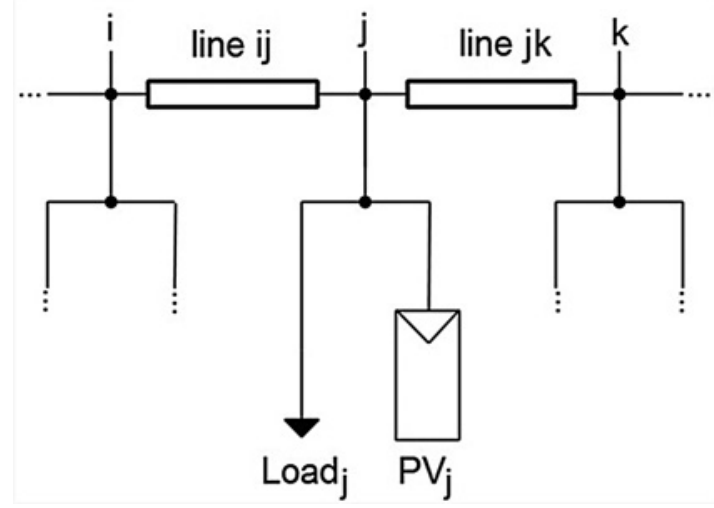

Fig. 2 Detail of the elements in node $j$

high power STATCOM. All cases are analysed with respect to the grid described in the previous section.

\subsection{Control strategy 1}

The control strategy 1 corresponds to the case where no reactive power control method applies. It is included here only for comparative purposes and permits observing the voltage profile along the LV grid. Fig. 3 shows the measured voltage and reactive power at each inverter for this scenario. By looking at the top sub-figure, it can be noted that the distance between the power source and the nodes has a significant influence on the voltage profile. In fact, the impedance seen from each node to the source increases with distance and, as a consequence, the voltage also increases. The only nodes whose voltages break this tendency are nodes 12 to 16 , in which the voltage is reduced due to the effect of the meshed configuration. Obviously, the bottom sub-figure shows that all nodes have their reactive power at zero because no reactive power control method applies.

\subsection{Control strategy 2}

The control strategy 2 is based on the conventional droop function used in power systems to coordinate the injection of reactive

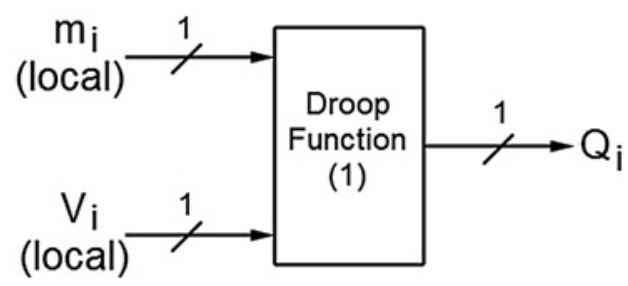

Fig. 4 Diagram of the control strategy 2

power among several distributed generators. Recently, this technique has been also employed in LV grids to prevent the over voltage problem $[19,20]$. With the droop method, the reactive power $Q_{i}$ is calculated by the local measured voltage $V_{i}$ as indicated in (1)

$$
Q_{i}=m_{i} \cdot\left(V_{i}-1\right)
$$

where $V_{i}$ is expressed in p.u. (per unit) and $m_{i}$ is the slope of the proportional droop method. Fig. 4 illustrates a diagram for this control strategy that is implemented in each inverter. Note that no communication network is needed to implement the droop technique.

Fig. 5 depicts the measured voltage and absorbed (negative) reactive power when using the control strategy 2 . As expected, it is interesting to note in the top sub-figure that the voltages decrease compared with the results obtained with the control strategy 1 because in this case voltage regulation takes place. In addition, the absorption of reactive power (bottom sub-figure) follows the profile of the voltage but such as a mirror curve effect, which is the standard situation observed in systems employing the droop method when the grid is characterised as explained in Section 2.

\subsection{Control strategy 3}

Strategy 3 includes the first new networked reactive power control method presented in this paper. It is based on a two level control, as illustrated in the block diagram of Fig. 6. The primary level, named local control (on the right-hand side of the block diagram),
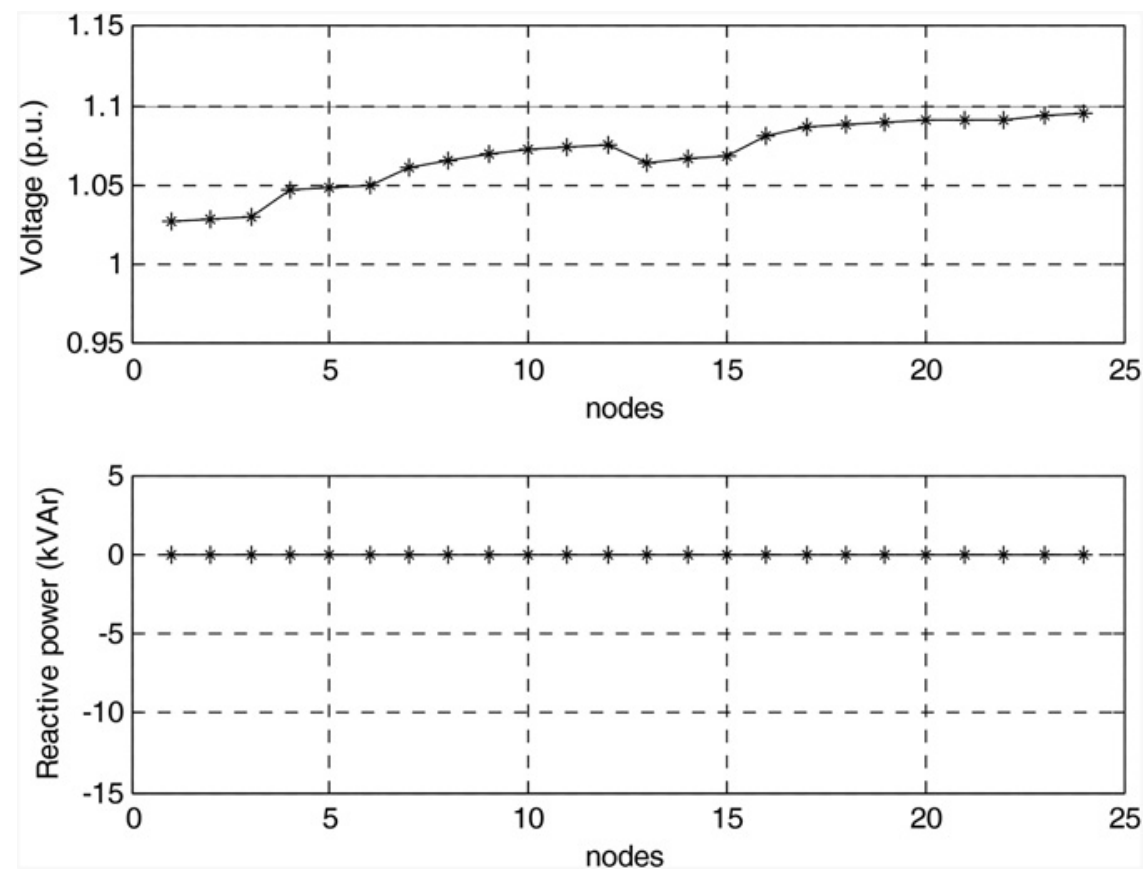

Fig. 3 Voltage and reactive power using the control strategy 1 

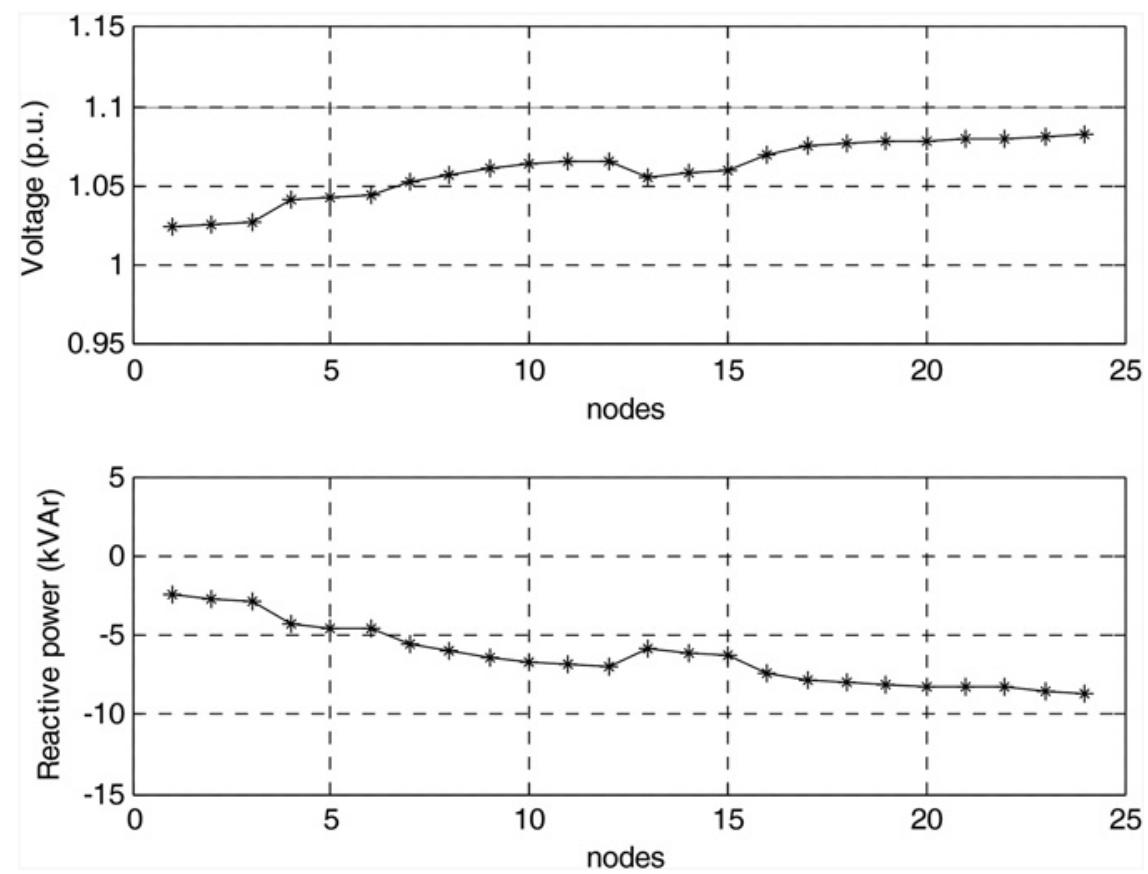

Fig. 5 Voltage and reactive power using the control strategy 2

is still the droop control method implemented in each inverter and based on voltage regulation through $Q$, as indicated in (1) but with a new slope $m_{\mathrm{a}}$.

The second control level, named distributed control, is designed to fulfil an additional control objective which aims to provide an equal distribution of the reactive power absorbed by each inverter. The motivation behind this policy is to have all inverters contributing with the same effort that is suffering the same stress. To achieve this goal, communication between inverters is required following a multi-master paradigm. Each inverter broadcasts the reactive power that is injecting or absorbing. Hence, all inverters receive all the data about the measured reactive power and, as illustrated in the left-hand side of the block diagram of Fig. 6, generate the average reactive power using all received reactive power $Q_{j}$ and their own measure $Q_{i}$, as indicated in (2)

$$
Q_{\mathrm{avg}}=\frac{1}{n} \sum_{i=1}^{n} Q_{i}
$$

where $n$ is the number of nodes. Then $Q_{\text {avg }}$ is supplied to a proportional + integral (PI) compensator, as indicated in (3)

$$
m_{d}=K_{p, Q} \cdot\left(Q_{\text {avg }}-Q_{i}\right)+K_{i, Q} \int\left(Q_{\text {avg }}-Q_{i}\right) \mathrm{d} t
$$

being $K_{p, Q}$ and $K_{i, Q}$ the gains of the compensator. The PI controller (3) is responsible for achieving the reactive power equalisation. Note that the output of the compensator $m_{d}$ is added to the local slope $m_{i}$ to update the slope value of the conventional droop function $m_{\mathrm{a}}$. Hence, from an implementation point of view, all inverters implement the droop method as well as the operations indicated by (2) and (3). In other words, the distributed control is implemented in all inverters.

Fig. 7 depicts the measured voltage and reactive power when using control strategy 3 (being $K_{p, Q}=0.1$ and $K_{i, Q}=12$ ). The voltage is similar to the results obtained in the previous section, but the profile of the reactive power is now equalised. The transient response of the system start-up is shown in Fig. 8. At the beginning of the experiment (from $t=0 \mathrm{~s}$ to $t=1 \mathrm{~s}$ ), the reactive power control is intentionally disabled. From $t=1 \mathrm{~s}$ to $t=2 \mathrm{~s}$, the droop method is activated but only with local data (i.e. $m_{\mathrm{a}}=m_{i}$ ). Therefore, during this interval, the absorbed reactive power is different at each inverter. Finally, at $t=2 \mathrm{~s}$, the control strategy 3 is activated and the reactive powers at each inverter achieve the same steady state value following different transient responses.

\subsection{Control strategy 4}

Strategy 4 constitutes the second new networked reactive power control method presented in this paper. Such as in the previous strategy, the droop method is still implemented in each inverter. However, in this case, the slope of the proportional droop controller given in (1) is updated following a completely different approach than the previous PI (3). First of all, the additional objective pursued by this new strategy is the minimisation of power losses in the whole system, including power losses in the underground cables

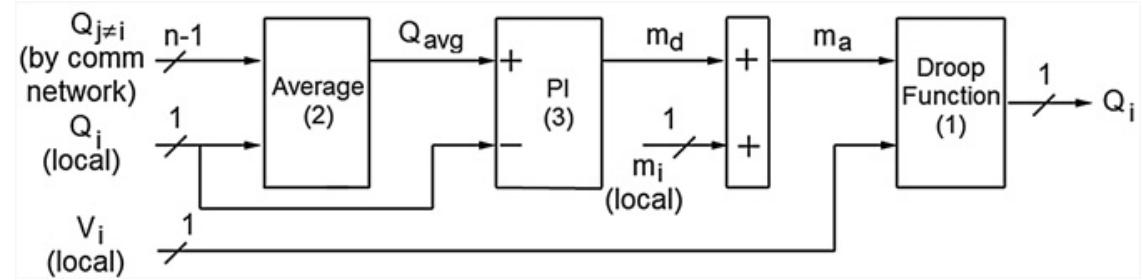

Fig. 6 Diagram of the control strategy 3 

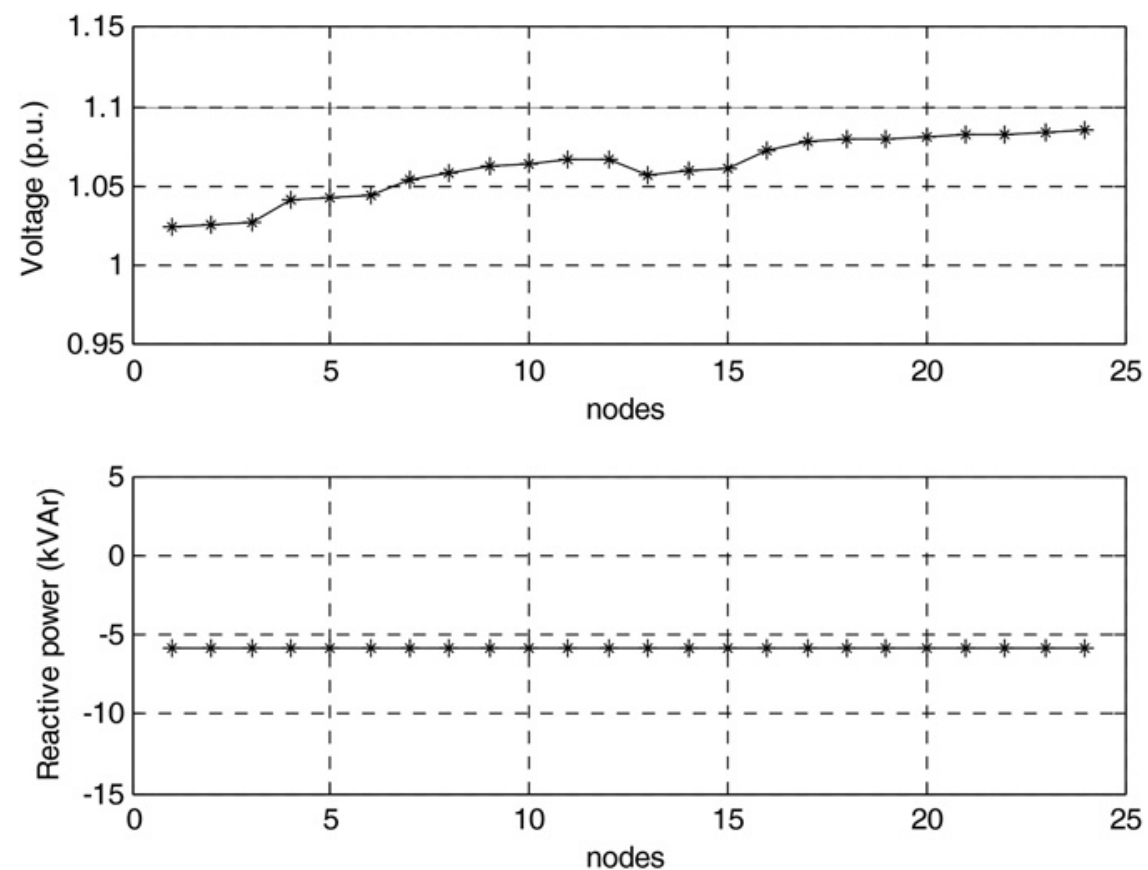

Fig. 7 Voltage and reactive power using the control strategy 3

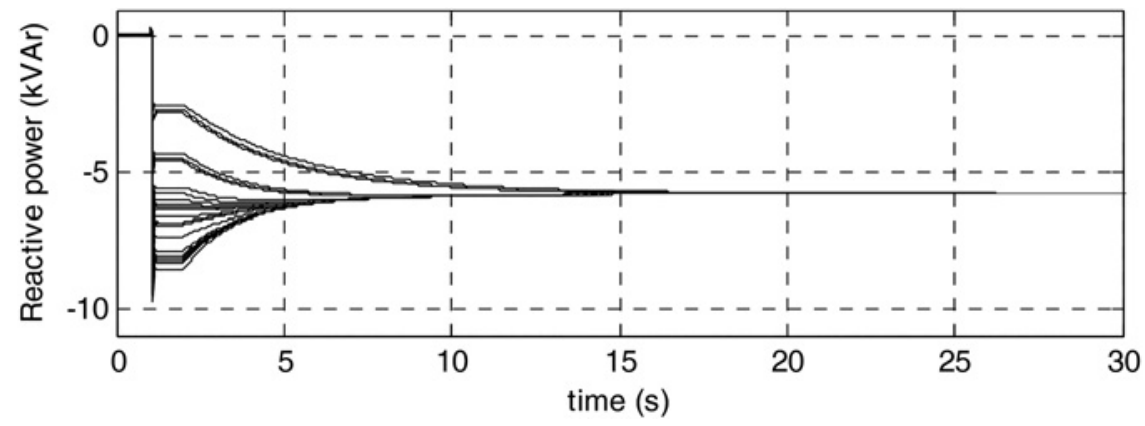

Fig. 8 Transient response of the system start-up using the control strategy 3

and in the PV inverters. Second, the communication paradigm that is employed is based on a master/slave configuration.

Fig. 9 shows the diagram of the new control strategy for the networked control system. A central database located in the master side is used here and receives all the active power $P_{i}$ that each inverter is injecting. Then, the master determines the optimal droop slope increments $m_{\mathrm{c}}$ to be added to each original slope $m_{i}$ to have minimum power losses in the system for any combination of the power production in the PV generators. The problem with this control strategy is to find the appropriate values of $m_{\mathrm{c}}$ that minimise the power losses with enough accuracy.

The solution to the mentioned problem can be obtained by using several non-linear optimisation techniques including those described in Section 1 [24-29]. However, in this paper, the Nelder-Mead non-linear minimisation method is employed due to its easy application [37]. In particular, a recursive program using the MATLAB ${ }^{\odot}$ fminsearch function has been specifically developed for the performance evaluation of the study presented below.

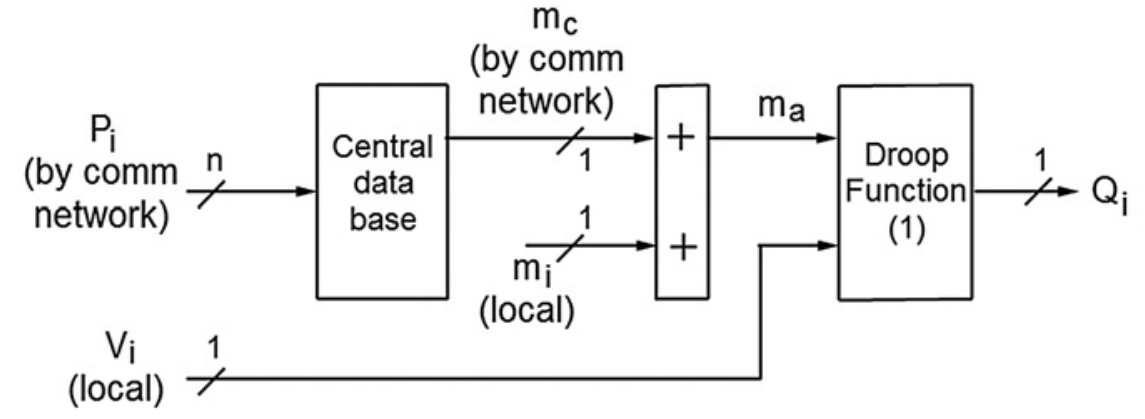

Fig. 9 Diagram of the control strategy 4 

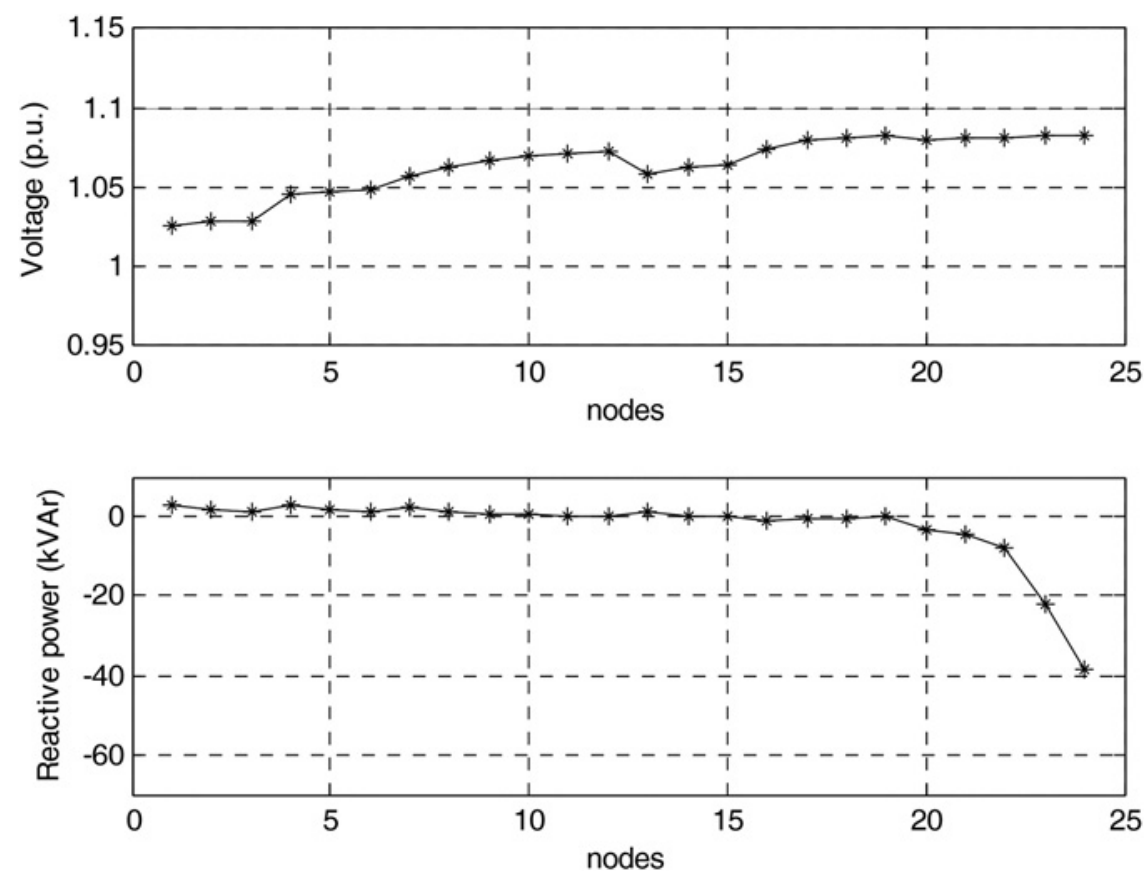

Fig. 10 Voltage and reactive power using the control strategy 4

An interesting issue regarding this policy refers to its implementation. First of all, it has to be decided which is the trigger condition that mandates to update the local droop slopes. In other words, which differences in active power injection are allowed without updating the local controls. Second, depending on the computational overhead of the implemented algorithm in the master node, two different approaches are foreseen. In the first one, when the computational overhead is low, the optimal $m_{\mathrm{c}}$ could be computed online in the master node and sent to each inverter whenever required. The second one, when the computational overhead is high, the optimal $m_{\mathrm{c}}$ for each inverter should be computed offline according to the production profiles, and stored in the master acting then as a central database. In the latter approach, different set of slopes for different profiles could be stored. In system operation, slopes updates could be sent whenever required. For this strategy, regardless of the implementation approach, the communication requirements would be the same.

The optimisation problem to compute the optimal slopes increments for each droop function aims at minimising the power losses. Knowing the voltage profile of the grid given in Fig. 3 when no reactive control method is applied, the cost function (CF) given to the fminsearch algorithm is written as

$$
\mathrm{CF}=P_{\text {losses }}+k\left(V_{24}^{*}-V_{24}\right)^{2}
$$

where $k=1000$ and $P_{\text {losses }}$ are measured in the MATLAB ${ }^{\odot}$ model as the difference between the power production and the active power injected into the grid. The regulation term $k$ in (4) ensures that the node with the higher voltage (node 24 in this study) is stabilised to a pre-defined reference voltage $V_{24}^{*}$. To make the performance comparison among the control strategies easy, the reference voltage is chosen to be here as the maximum voltage of the control strategy 2 . In a practical scenario, the reference voltage could be designed following a different approach. In fact, this parameter should be viewed as an additional degree of freedom of this control strategy.

It is also interesting to note that the second term in (4) forces inverters to absorb reactive power. In other words, removing this term of the CF results in a set of slopes $m_{\mathrm{c}}$ that give a solution in which the reactive power absorbed by the PV inverters is nearly zero. Obviously, in this situation the power losses are minimal.
However, in this case no reactive power regulation is provided and over voltage problem could still appear.

Fig. 10 shows the measured voltage and reactive power when using the control strategy 4 . Note that, although the voltage profile is different when using the control strategy 2 (see Fig. 5), the voltage at node 24 coincides in both cases. In addition, the absorption of reactive power that minimises the power losses is mainly carried out by only five PV generators (those located at nodes $20,21,22,23$, and 24). This fact suggests that in the analysed situation, the reactive control algorithm could be disabled in most of the PV generators with only a small penalty in the power losses. Fig. 11 shows the evolution of the CF. Note that, from step 1350 , the reduction in the CF is nearly negligible, reaching at this step the solution to the optimisation problem.

\subsection{Control strategy 5}

The results obtained with the use of control strategy 4 suggest that most of the PV inverters could have the reactive power control algorithm disabled. The five active inverters (from 20 to 24) absorb all the necessary reactive power and thus they should be designed with a higher power rating than the other inverters. Following this idea, the extreme situation could be to consider only one high power rated inverter absorbing all the reactive power. This scenario can also be implemented using a high power STATCOM assuming the responsibility of absorbing all the reactive power. In this case, all the inverters would have the same power rating which is an interesting feature from the point of view of maintenance and replacement. According to Fig. 10, the STATCOM should be located at node 24 . With this system design, the inverters do not need reactive power control loops, the communication infrastructure is not required, and only a local voltage regulation loop is necessary at the STATCOM.

This scenario has been also considered to be of interest to the comparative performance analysis that is presented in this paper. Although the use of STATCOM is not really new, the optimal-inspired location that can be derived from strategy 4 makes its inclusion worth for comparison. In fact, the practical application of control strategy 5 in different LV distribution grids requires, as a previous design step, the analysis of the reactive power absorption provided by the control strategy 4 to determine the best location of the high power STATCOM. 


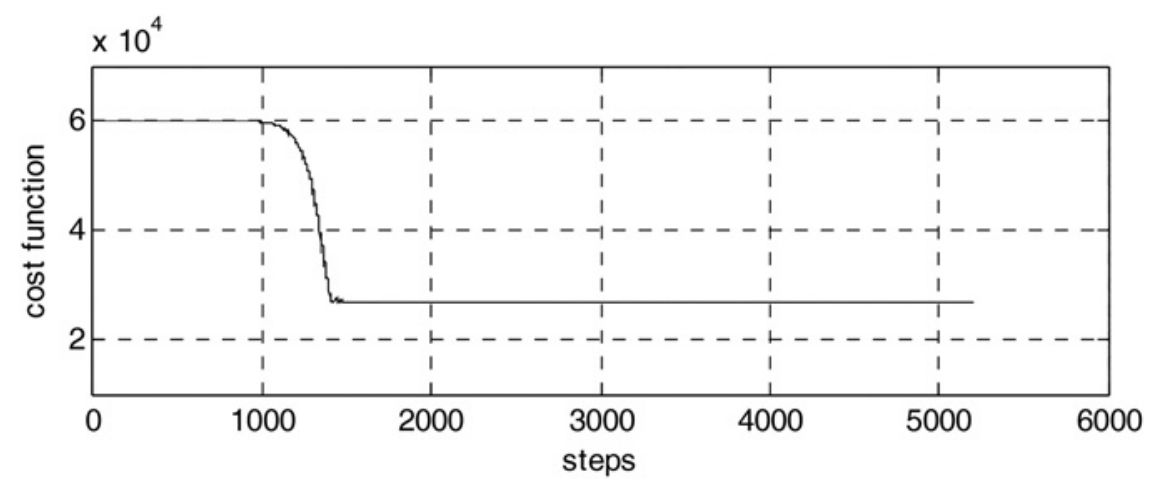

Fig. 11 Evolution of the $C F$ in the control strategy 4

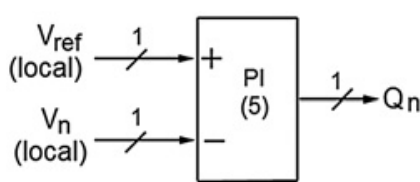

Fig. 12 Diagram of the control strategy $5(n=24$ in this study)

The diagram of the linear control scheme for the proposed control strategy 5 is shown in Fig. 12. It consists of a simple PI compensator implemented in node 24 as expressed in (5)

$$
Q_{n}=K_{p, V} \cdot\left(V_{\text {ref }}-V_{n}\right)+K_{i, V} \int\left(V_{\text {ref }}-V_{n}\right) \mathrm{d} t
$$

where $K_{p, V}$ and $K_{i, V}$ are the PI gains and $n=24$ in this study. To simplify the comparison among control strategies, the reference voltage $V_{\text {ref }}$ is chosen again as the maximum voltage of the control strategy 2. Note also that the droop control method is not employed for this single compensator.

Fig. 13 shows the measured voltage and reactive power when using the control strategy $5\left(K_{p, V}=0.1\right.$ and $\left.K_{i, V}=12\right)$. The reactive power is exactly zero in all inverters and the STATCOM absorbs the necessary reactive power to regulate the voltage at node 24 . As expected, this voltage coincides with the measured value when using the control strategy 2 .

\section{Results and discussion}

In this section, the performance of the five reactive power compensation techniques is compared. The merit factors are the maximum voltage across the distribution grid, the power factor in the point of common coupling, and the total power losses in the installation. In addition, a qualitative economical cost is also included in the comparison.

Ideally the best strategy should be one accomplishing the following objectives:

(i) the voltage across the distribution grid is minimum,

(ii) the power factor in the point of common coupling is maximum (unity),

(iii) the power losses in the power system are minimum,

(iv) and the extra cost to get these features is minimum (zero).

Unfortunately, none of the considered strategies fulfil these four objectives simultaneously. Below is a discussion on the results provided by the control strategies and an attempt to identify the best strategy considering the ideal features listed above.
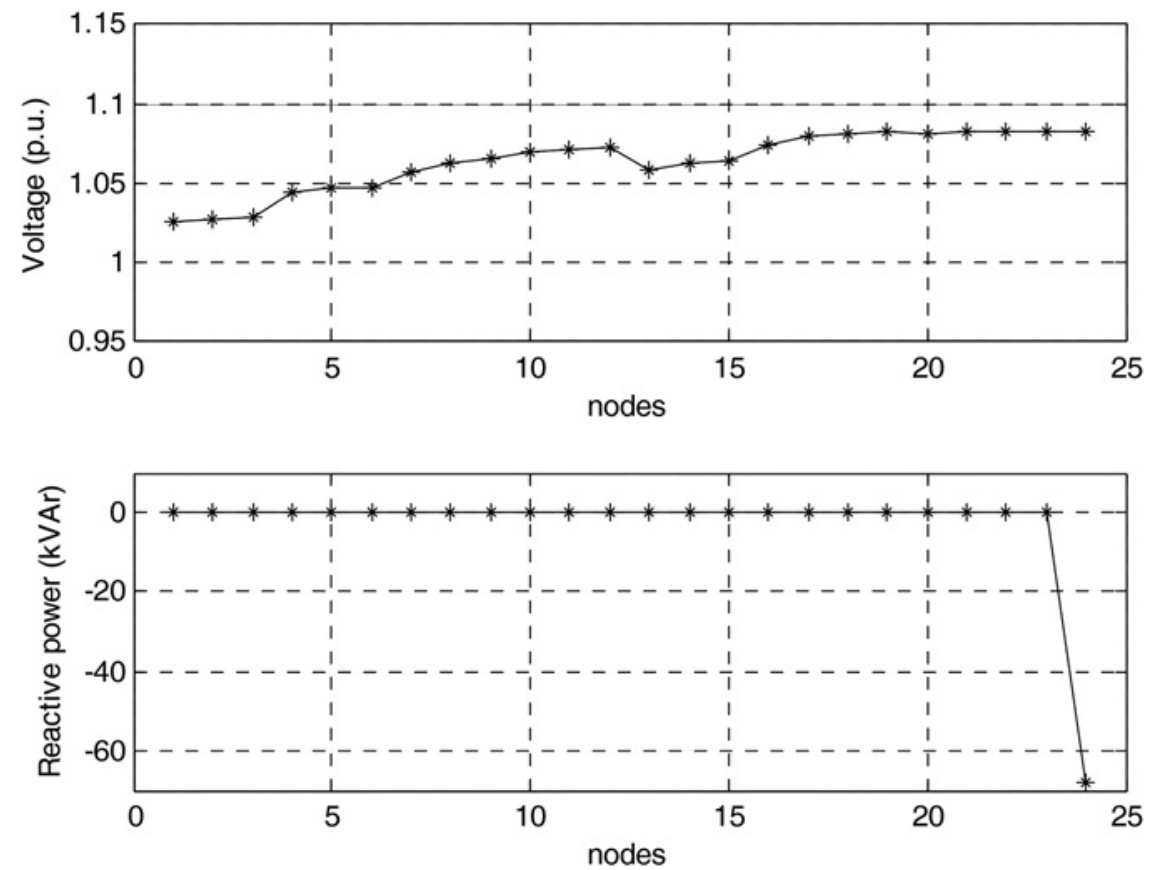

Fig. 13 Voltage and reactive power using the control strategy 5 
Table 2 Merit factors and cost estimation for the comparison of the control strategies

\begin{tabular}{lcccc}
\hline Strategy & Vimax, p.u. & PF & Losses, \% & Extra cost \\
\hline 1 & 1.0954 & 0.9998 & 6.5813 & 0 \\
2 & 1.0825 & 0.9000 & 8.1385 & 0 \\
3 & 1.0861 & 0.9226 & 7.5769 & low \\
4 & 1.0825 & 0.9812 & 7.5087 & high \\
5 & 1.0825 & 0.9755 & 7.5976 & medium \\
\hline
\end{tabular}

Table 2 shows the measured results for the control strategies. Moreover the qualitative cost estimation is included to enrich comparison. The control strategy 1 provides the base values for the merit factors: the maximum voltage is slightly lower than the limit value (1.1 p.u.) [38]; the power factor is unity, which means that no reactive power absorption is done with this technique; and the power losses are minimum (compared with the rest of strategies). Note that three of the four listed objectives are achieved. Therefore no reactive power absorption is a good strategy if the maximum voltage is not exceeded. The problem with strategy 1 is that no action is taken to prevent the voltage excess, thus voltage overshoot could not be avoided.

The power factor with the control strategy 2 is 0.9 . This is the minimum power factor accepted in the point of common coupling to limit the loading of the coupling transformer. The values of the local slopes $m_{i}$ for the droop functions have been designed for this control strategy to guarantee the achievement of this power factor $\left(m_{i}=104,600\right)$. These values have been maintained unchanged for the rest of the control strategies. The absorption of reactive power reduces the maximum voltage to 1.0825 p.u., but also produces a significant increase in the power losses. The advantage of this control strategy is that the voltage reduction is achieved with no penalty in the economic cost of the installation because no extra cost is required to implement the local droop function in the digital controllers of each PV inverter. Although only two objectives are achieved (minimum voltage and no extra cost), strategy 2 is considered better than strategy 1 as it provides voltage regulation in the inverters, thus preventing the over voltage problem

The power factor with control strategy 3 is 0.9226 . This means that the reactive power absorbed by the installation is lower in this case compared with control strategy 2 . That is, lower total reactive power is required to equalise the local reactive power absorbed by each PV inverter. The consequence of this decrease in reactive power absorption is a penalty in the voltage reduction (the measured maximum voltage is higher with this technique). With lower reactive power absorption, the power losses are also reduced in comparison with control strategy 2 . However, the deployment of a communication infrastructure is necessary to implement control strategy 3 which produces a small increase in the economic cost of the installation. It is worth mentioning that none of the control objectives listed above is achieved with this technique. Therefore, this networked control system produces inferior results compared with the local control (with no communication) provided by control strategy 2 .

The maximum voltage measured with control strategy 4 is as low as 1.0825 p.u., thus coinciding with the good result obtained with control strategy 2 . In addition, this result is achieved with lower reactive power absorption (observe that the power factor is very high in comparison with the measured value for the control strategy 2), which reduces the power losses. To be more precise, a reduction of $7.7 \%$ in power losses is obtained in control strategy 4 in comparison with control strategy 2. This performance improvement is reached with a significant increment in the economic cost of the installation. The reactive power profile with control strategy 4 suggests that five high power rating inverters should be employed in nodes 20 to 24 , incurring in an extra cost compared with the previous strategies. Therefore, control strategy 4 is the best strategy from a technical viewpoint. However, it is also the one that requires the higher investment.
The maximum voltage with control strategy 5 is also 1.0825 p.u. Thus the measured power factor and power losses can be easily compared with control strategies 2 and 4 . In particular, a reduction of $6.6 \%$ in power losses in comparison with control strategy 2 is obtained given that lower reactive power is absorbed in this case. This also denotes slightly higher absorption of reactive power in comparison with control strategy 4. Summing up, the results of control strategies 4 and 5 are very similar. However, the extra cost estimated for control strategy 5 is lower. Note that in this case no communication infrastructure is required and only one extra high power converter (instead of five) is necessary.

\section{Conclusion}

Two new reactive power compensation techniques have been proposed in this study to alleviate the over voltage problem existing in LV grids with high penetration of PV technology. Both techniques are based on a networked control system with low-bandwidth communication infrastructure. The first proposal (named strategy 3) is a linear control scheme with a multi-master communication approach between the PV inverters. The second proposal (named strategy 4) is based on a non-linear control scheme trained to minimise the power losses in the installation and implemented with a master-slave communication approach.

Moreover a thorough and useful comparison reference framework has been developed for future LV network design. This framework is applied to new and existing compensating techniques including the conventional droop method (strategy 2), the new proposals (strategies 3 and 4), and a single STATCOM with simple linear control and no communication requirements (strategy 5), but with an optimal-inspired location within the installation.

The concluding remarks of the comparative study are listed below:

(i) Strategy 2 achieves minimum voltage in the distribution grid with any extra economical cost. However, these good results are achieved absorbing maximum reactive power and thus penalising the efficiency of the installation. This technique should be considered as a good candidate when the cost is a main concern in the system design.

(ii) The practical use of control strategy 3 is limited due to its inability to reduce the maximum voltage compared with the control techniques 2,4 , and 5 .

(iii) The best technical solution for the LV distribution grid under study is control strategy 4 . The price to pay for this superior performance is an excessive extra economical cost to both acquire five high power rating inverters and implement the communication infrastructure.

(iv) A good solution for the LV distribution grid is also control strategy 5 with only slightly lower measured results. The need of only one high power converter (instead of five) and the fact that no communication infrastructure is required reduces drastically the extra cost of this solution. Thus it should be considered as a good candidate for the final design.

\section{Acknowledgments}

This work was partially supported by the Ministerio de Economia y Competitividad of Spain and Feder Founds under projects ENE2012-37667-C02-02，CICYT DPI2010-18601 and TEC 2013-46938-R.

\section{References}

1 Wu, X., Bliss, M., Sinha, A., et al.: 'Distributed electrical network modelling approach for spatially resolved characterisation of photovoltaic modules', IET Renew. Power Gener., 2014, 8, (5), pp. 459-466

2 Sara, I.D., Betts, T.R., Gottschalg, R.: 'Determining spectral response of a photovoltaic device using polychromatic filters', IET Renew. Power Gener., $2014,8,(5)$, pp. $467-473$ 
3 Al-Sabounchi, A., Gow, J., Al-Akaidi, M.: 'Simple procedure for optimal sizing and location of a single photovoltaic generator on radial distribution feeder', IET Renew. Power Gener., 2014, 8, (2), pp. 160-170

4 Jabr, R.A.: 'Minimum loss operation of distribution networks with photovoltaic generation', IET Renew. Power Gener., 2014, 8, (1), pp. 33-44

5 Khare, A., Rangnekar, S.: 'Optimal sizing of a grid integrated solar photovoltaic system', IET Renew. Power Gener., 2014, 8, (1), pp. 67-75

6 Faraji, R., Rouholamini, A., Naji, H.R., et al.: 'FPGA-based real time incremental conductance maximum power point tracking controller for photovoltaic systems', IET Power Electron., 2014, 7, (5), pp. 1294-1304

7 Hamid, M.I., Jusoh, A., Anwari, M.: 'Photovoltaic plant with reduced output current harmonics using generation-side active power conditioner', IET Renew. Power Gener., 2014, 8, (7), pp. 817-826

8 Kim, K.-T., Kwon, J.-M., Kwon, B.-h.: 'Parallel operation of photovoltaic power conditioning system modules for large-scale photovoltaic power generation', IET Power Electron., 2014, 7, (2), pp. 406-417

9 Thomson, M., Infield, D.G.: 'Impact of widespread photovoltaics generation on distribution systems', IET Renew. Power Gener., 2007, 1, (1), pp. 33-40

10 Lin, B.-R., Huang, C.-L.: 'Analysis and implementation of an integrated sepic-forward converter for photovoltaic based light emitting diode lighting', IET Power Electron., 2009, 2, (6), pp. 635-645

11 Delfino, F., Procopio, R., Rossi, M., et al.: 'Integration of large-size photovoltaic systems into the distribution grids: ap-qchart approach toassess reactive support capability', IET Renew. Power Gener., 2010, 4, (4), pp. 329-340

12 Roscoe, A.J., Ault, G.: 'Supporting high penetrations of renewable generation via implementation of real-time electricity pricing and demand response', IET Renew. Power Gener., 2010, 4, (4), pp. 369-378

13 Jiang, Y., Abu Qahouq, J.A.: 'Single-sensor multi-channel maximum power point tracking controller for photovoltaic solar systems', IET Power Electron, 2012, 5, (8), pp. 1581-1592

14 Yang, B., Li, W., Zhao, Y., et al.: 'Design and analysis of a grid-connected photovoltaic power system', IEEE Trans. Power Electron, 2010, 25, (4), pp. $922-1000$

15 Testa, A., De Caro, S.: 'Active voltage ripple compensation in PV Systems for domestic uses'. Proc. IEEE Int. Symp. Industrial Electronics, Bari, July 2010, pp. 2193-2198

16 Kjaer, S.B., Pedersen, J.K., Blaabjerg, F.: 'A review of single-phase grid-connected inverters for photovoltaic modules', IEEE Trans. Ind. Appl., 2005, 41, (5), pp. $1292-1306$

17 Dasgupta, S., Sahoo, S.K., Panda, S.K.: 'Design of a Spatial iterative learning controller for single phase series connected PV module inverter for grid voltage compensation'. Proc. 2010 Int. IPEC Conf. Power Electronics, Sapporo, June 2010, pp. 1980-1987

18 Conti, S., Greco, A., Messina, N., et al:: 'Local voltage regulation in LV distribution networks with PV distributed generation'. Int. Symp. Power Electronic, Electrical Drives, Automation and Motion, Taormina, May 2006, pp. 519-524

19 Turitsyn, K., Sulc, P., Backhaus, S., et al.: 'Local control of reactive power by distributed photovoltaic generators'. Proc. First IEEE Int. Conf. Smart Grid Comm., Gaithersburg, October 2010, pp. 79-84

20 Demirok, E., Casado Gonzalez, P., Frederiksen, K.H.B., et al.: 'Local reactive power control methods for overvoltage prevention of distributed solar inverters in low-voltage grids', IEEE J. Photovoltaics, 2011, 1, (2), pp. 174-182

21 Li, L., Hu, Z., Hu, M., Zheng, J., Zhu, L., He, L., Zhang, C.: 'HGPSO based reactive power optimization of distribution network with photovoltaic generation'. Proc. 2012 Asia Pacific, Conf. Power and Energy Engineering, Shanghai, China, March 2012, pp. 1-4

22 Libo, W., Zhengming, Z., Jianzheng, L.: 'A single-stage three-phase grid-connected photovoltaic system with modified MPPT method and reactive power compensation', IEEE Trans. Energy Convers., 2007, 22, (4), pp. 881-886

23 Yazdani, A., Dash, P.P.: 'A control methodology and characterization of dynamics for a photovoltaic (PV) system interfaced with a distribution network', IEEE Trans. Power Deliv., 2009, 24, (3), pp. 1538-1551

24 Shah, N., Chudamani, R.: 'Grid interactive PV system with harmonic and reactive power compensation features using a novel fuzzy logic based MPPT'. Proc. IEEE Int. Conf. Industrial and Information Systems, Chennai, August 2012, pp. 1-6

25 Zhu, J.Z., Chang, C.S., Yan, W., et al.: 'Reactive power optimisation using an analytic hierarchical process and a nonlinear optimisation neural network approach', Proc. IEE Gener. Transm. Distrib., 1998, 145, (1), pp. 89-97

26 Al-Saedi, W., Lachowicz, S.W., Habibi, D.: 'An optimal current control strategy for a three-phase grid-connected photovoltaic system using Particle Swarm Optimization'. Proc. IEEE Int. Conf. Power Engineering and Automation, Wuhan, September 2011, pp. 286-290

27 Viswanadha Raju, G.K., Bijwe, P.R.: 'Reactive power/voltage control in distribution systems under uncertain environment', IET Gener. Transm. Distrib., 2008, 2, (5), pp. 752-763

28 Senjyu, T., Miyazato, Y., Yona, A., et al.: 'Optimal distribution voltage control and coordination with distributed generation', IEEE Trans. Power Deliv., 2008, 23, (2), pp. 1236-1242

29 Niknam, T., Zare, M., Aghaei, J.: 'Scenario-based multiobjective Volt/Var control in distribution networks including renewable energy sources', IEEE Trans. Power Deliv., 2012, 27, (4), pp. 2004-2019

30 Baran, M.E., El-Markabi, I.M.: 'A multiagent-based dispatching scheme for distributed generators for voltage support on distribution feeders', IEEE Trans. Power Syst., 2007, 22, (1), pp. 52-59

31 Bottura, R., Borghetti, A.: 'Simulation of the Volt/Var control in distribution feeders by means of a networked multiagent system', IEEE Trans. Ind. Inform. 2014, 10, (4), pp. 2340-2353

32 Indumathi, R., Venkateshkumar, M., Raghavan, R.: 'Integration of D-Statcom based photovoltaic cell power in low voltage power distribution grid'. Proc. 2012 Int. ICAESM Conf. Advances in Engineering, Science and Management, Nagapattinam, Tamil Nadu, March 2012, pp. 460-465

33 Varma, R.K., Khadkikar, V., Seethapathy, R.: 'Nighttime application of PV solar farm as STATCOM to regulate grid voltage', IEEE Trans. Energy Convers, 2009 24, (4), pp. 983-985

34 Dallmer-Zerbe, K., Biener, W., Wille-Haussmann, B. 'Reactive power control in low voltage distribution grids: comparison of centralized and decentralized $Q$ $(U)$-controller designs based on probabilistic power flow analysis'. Proc. Int. Congress Security in Critical Infrastructures Today, 2013, pp. 1-6

35 Van Pham, H., Rueda, J.L., Erlich, I. 'Probabilistic evaluation of voltage and reactive power control methods of wind generators in distribution networks', IET Renew. Power Gener., 2015, 9, (3), pp. 195-206

36 Demirok, E., Casado González, P., Frederiksen, K.H.B., et al.: 'Local reactive power control methods for overvoltage prevention of distributed solar inverters in low-voltage grids', IEEE J. Photovoltaics, 2011, 1, (2), pp. 174-182

37 Lagarias, J.C., Reeds, J.A., Wright, M.H., et al.: 'Convergence properties of the Nelder-Mead simplex method in low dimensions', SIAM J. Optim., 1998, 9, (1), pp. 112-147

38 Characteristics of the Utility Interface for Photovoltaic (PV) Systems, IEC61727, December 2004 